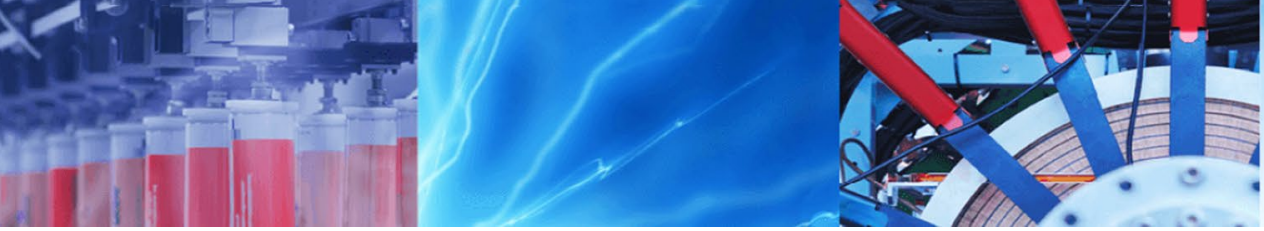

Research Article

\title{
Evaluation of a commercial MR damper for application in semi-active suspension
}

\author{
Rangaraj Madhavrao Desai ${ }^{1} \cdot$ Mohibb E. Hussain Jamadar ${ }^{1} \cdot$ Hemantha Kumar $^{1}$. Sharnappa Joladarashi ${ }^{1}$. \\ S. C. Rajasekaran² · G. Amarnath ${ }^{2}$
}

(c) Springer Nature Switzerland AG 2019

\begin{abstract}
As the rheology of a magneto-rheological (MR) fluid can be controlled by an externally applied magnetic field, the damping force generated by a MR damper can be controlled by varying the current supplied to an electromagnet inside the damper. This paper presents the experimental evaluation of such a MR damper RD-8040-1 by Lord Corporation, USA, and its application in a semi-active suspension. The experiments were carried out in damping force testing machine. Sinusoidal displacement input was given to the test damper. The set of experiments were repeated for different levels of current (0-1.5 A in steps of $0.25 \mathrm{~A}$ ) supplied to the MR damper. Plots of force versus displacement for each frequency of excitation and plots of maximum force versus frequency of excitation show that higher values of current lead to elevated values of MR damper forces. This increase in MR damper load with current supplied is studied and analyzed to develop a mathematical model of the MR damper under investigation. The nonlinear softening hysteretic behavior of the MR damper is simulated by using genetic algorithm provided in the optimization toolbox of MATLAB. Calculations on energy dissipation and equivalent damping coefficient of the MR damper show that the same damper can make the suspension system behave as an underdamped system, critically damped system or overdamped system depending on the value of current supplied to it. The application of this MR damper for heavy vehicle driver's seat suspension is explored with the help of MATLAB simulations.
\end{abstract}

Keywords MR damper · Semi-active suspension · Lord RD-8040-1 · Seat suspension · Magneto-rheological fluid

\section{Introduction}

The purpose of any suspension system is to isolate a structure from external excitations. RD-8040-1 is a magnetorheological (MR) damper manufactured by Lord Corporation, USA. According to the product technical data provided by Lord Corporation on their website, it is meant for suspension applications in industries and it provides damping which varies in real time in response to varying strength of the magnetic field. This is achieved by a rise in the MR fluid yield strength. The stroke length of the damper is $55 \mathrm{~mm}$, and extended length is $208 \mathrm{~mm}$. There are many examples of studies done on the behavior of MR dampers. Cortes et al. [1] characterized MR damper based on fluid properties such as applied current and damper design parameters. Force, velocity and displacement were determined using load cell and Shimadzu system. Zhang et al. [2] studied the importance of energy dissipated and controllable force in MR damper performance and hence concluded that both are strong functions of magnetic flux density that can be attained in MR fluid gap. Guan et al. [3] derived not only ordinary differential equations to represent the physical MR damper using the friction element, viscous element and spring element but also expression to determine the width of the hysteresis. Spencer et al. [4] reviewed various models available at that time and proposed a new model that could predict the working of a magnetic field-controllable MR fluid damper in a more

$\triangle$ Rangaraj Madhavrao Desai, rangarajmdesai@gmail.com | ${ }^{1}$ Department of Mechanical Engineering, National Institute of Technology Karnataka, Surathkal 575 025, India. ${ }^{2}$ Rambal Ltd, Thirukazhukunram Road, Thiruporur, Chennai, Tamil Nadu 603 110, India.

SN Applied Sciences (2019) 1:993 | https://doi.org/10.1007/s42452-019-1026-y

Received: 20 December 2018 / Accepted: 31 July 2019 / Published online: 6 August 2019 
effective manner. Bogdan [5] analyzed the parametric models of MR linear dampers concerning various behavioral characteristics. The analysis shows that the basic difficulties in formulating such models were because of the presence of hysteresis and jump-type phenomenon. It could be seen that if the model is too simple, then the predicted curves become less accurate, thus making the model ineligible to be used for control problems. Song et al. [6] used a series of continuous and differentiable mathematical functions to carry out nonparametric approach for modeling of MR damper. Dyke et al. [7] provided with a mathematical model to study the effect of parameters on vibration response of a MR damper characterized using Bouc-Wen model. Peng et al. [8] tried to describe the distorted hysteresis behavior of MR damper using Bouc-Wen-Baber-Noori method.

Very few researchers have applied the dissipation energy method to find the equivalent damping coefficient of a MR damper. In commercial load-carrying vehicles, passenger comfort is not a priority but low cost, ruggedness and vehicle reliability are the priority. Providing suspension system to the seat in addition to the vehicle suspension becomes important as the vehicle suspension cannot be made soft enough in order to maintain stability and roadholding of the commercial vehicle [9]. Application of MR dampers to a single-degree-of-freedom seat suspension in commercial vehicles is not fully explored and is not very well known.

\section{Methodology}

The flowchart of the methodology followed is shown in Fig. 1. A commercial MR damper was experimentally characterized on a damping force testing machine. The force developed by the damper at different frequencies of sinusoidal excitation for different values of current supplied was measured. Using the force-displacement curves thus obtained, the equivalent damping coefficient of the damper at different levels of current supplied is calculated. A mathematical model is developed for the MR damper behavior using the Bouc-Wen equations. A seat suspension using this MR damper was modeled, and its response to displacement pulse input at different values of current supplied is studied numerically using MATLAB Simulink toolbox.

\subsection{Experimental setup}

The commercial MR damper from Lord Corporation, model number RD-8040-1, was taken to Rambal India Ltd, Thiruporur, Chennai, for experimental testing in the damping force testing machine as shown in Fig. 2. The maximum load capacity of the testing machine is $1 \mathrm{~T}(1000 \mathrm{~kg})$, and

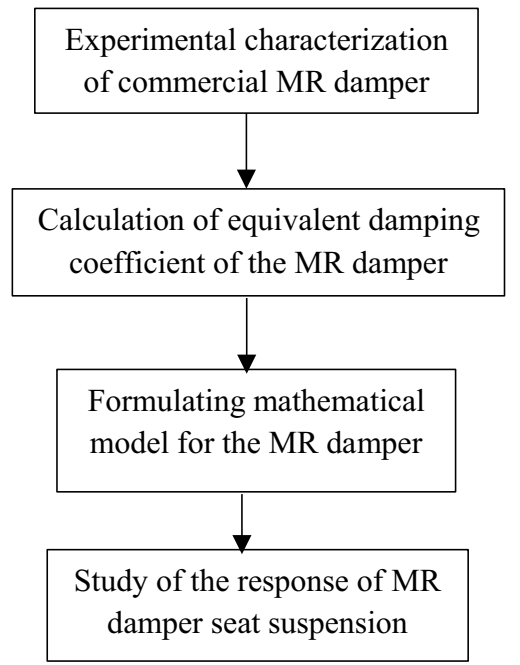

Fig. 1 Methodology flowchart

maximum velocity achievable is $1 \mathrm{~m} / \mathrm{s}$. The MR damper has a maximum stroke of $55 \mathrm{~mm}$, and its extended length is $208 \mathrm{~mm}$ [10].

By keeping the stroke fixed at $40 \mathrm{~mm}$ (amplitude of $20 \mathrm{~mm}$ ), the frequency of input oscillations was gradually increased to obtain different velocities. At each frequency and its corresponding velocity, different levels of current were given as input as shown in Table 1. During each test run, constant current was supplied to the magnetizing coil in the MR damper through the Wonder Box of Lord Corporation model RD-3002-03. The current being supplied was measured and verified using DC clamp current meter.

The different levels of sinusoidal input frequency and displacement amplitude were arrived at in consultancy with industrial collaborator Rambal Ltd who have a considerable amount of experience in manufacturing and testing hydraulic twin-tube and monotube dampers for various applications. Each experimental run was measured by sensors and logged by data acquisition system to give the instantaneous displacement and damping load for different frequencies of loading. The displacement (stroke in $\mathrm{mm}$ ) was measured by a position sensor in the hydraulic actuator, and the damping force was measured by a load cell mounted in series with the fixed jaw holding the other eye of the MR damper. Test runs were carried out at different levels of current supplied to the MR damper.

\subsection{Equivalent damping coefficient of the MR damper}

The area of the force-displacement plot of the damper gives the energy dissipated in one cycle of compression and extension. From the experimental plots of force versus displacement for the Lord MR damper at $2.07 \mathrm{~Hz}$ 


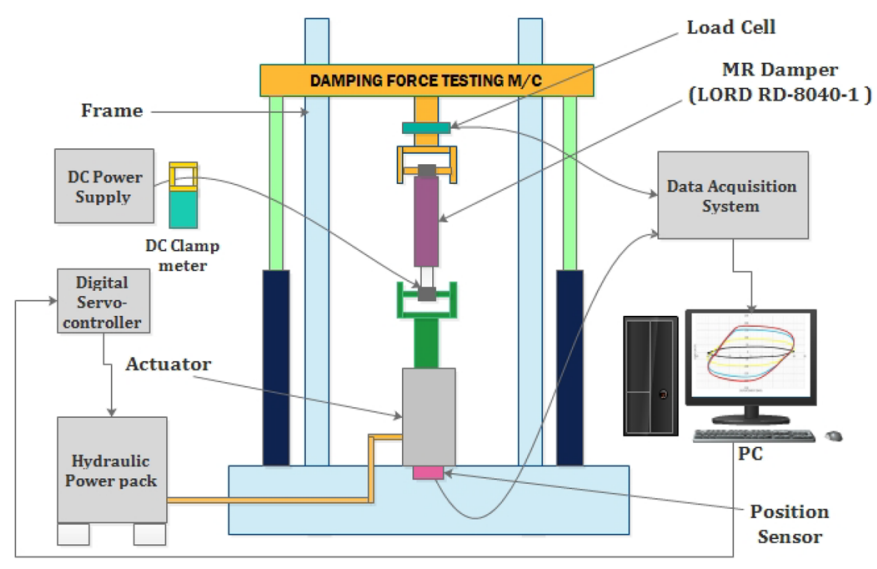

(a)

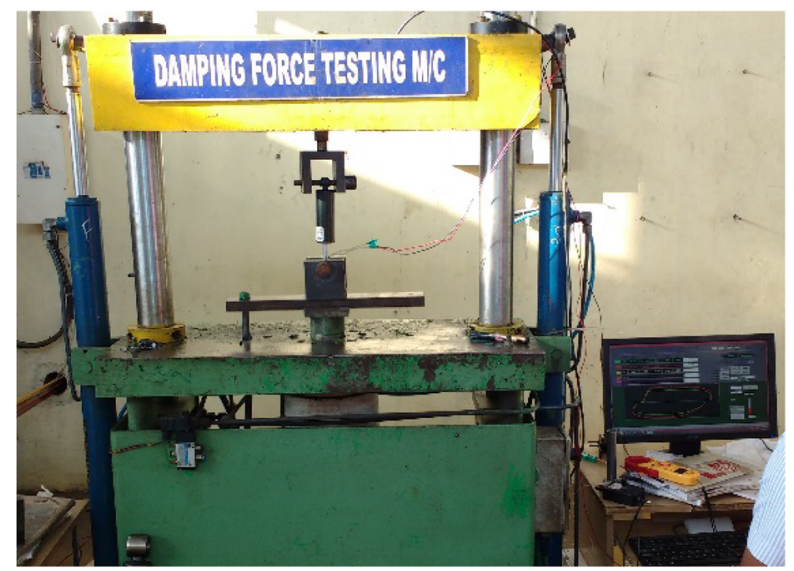

(b)

Fig. 2 a Schematic diagram of experimental setup. b Damping force testing machine

Table 1 Different levels of sinusoidal excitation frequency and current supplied at a fixed displacement amplitude of $20 \mathrm{~mm}$

\begin{tabular}{lll}
\hline $\begin{array}{l}\text { Sinusoidal input frequency } \\
f(\mathrm{~Hz})\end{array}$ & $\begin{array}{l}\text { Velocity amplitude } 2 \pi f X \\
(\mathrm{~m} / \mathrm{s})\end{array}$ & $\begin{array}{l}\text { Current } \\
\text { supplied } \\
\text { (A) }\end{array}$ \\
\hline 0.4 & 0.05 & 0 \\
1.03 & 0.13 & 0.25 \\
2.07 & 0.26 & 0.5 \\
3.1 & 0.39 & 0.75 \\
4.14 & 0.52 & 1 \\
& & 1.25 \\
& & 1.5 \\
\hline
\end{tabular}

excitation, area of the graph for one full cycle is calculated by numerical integration using the trapezoidal rule. Then using Eq. 1, the equivalent damping coefficient of the damper can be evaluated [11]. Here, $W$ is the singlecycle energy dissipation, $C_{\text {eq }}$ is the equivalent damping coefficient, $f$ is the frequency of excitation, and $X$ is the amplitude of excitation.

$W=2 \pi^{2} C_{\text {eq }} f X^{2}$

For a spring-mass system having a single degree of freedom, the critical damping coefficient is given by $C_{c}=2 \sqrt{\mathrm{km}}$, where $k$ is the stiffness of the spring and $m$ is the mass. The spring-mass damper system is critically damped if $C_{\text {eq }}$ is equal to $C_{c}$. A critically damped system returns to the mean position in the shortest time without overshooting to the other side of the abscissa. An underdamped system exhibits oscillatory motion with decreasing amplitude with time. An overdamped system also returns to the mean position without overshooting but takes longer time compared to the critically damped system.

\subsection{Mathematical model of MR damper}

Representation of behavior of MR damper as a mathematical model is required for simulation studies. The existing MR damper models are either nonparametric or parametric models. The parametric modeling technique uses a group of linear and nonlinear springs and other elements to characterize the behavior of the device. Based on mechanical idealizations, various parametric dynamic models for MR dampers have been explored and validated. Among these models, the Bouc-Wen model has gained wide acceptance within the engineering community as it can represent a wide range of hysteretic shapes by using simple differential equations [12]. Spencer et al. [4] first represented the hysteretic behavior of MR dampers by adopting the Bouc-Wen hysteretic operator. Simple Bouc-Wen can be shown schematically as in Fig. 3.

$F(t)=c_{0} x+k_{0}\left(x-x_{0}\right)+\alpha z$

$z=-\gamma|x| z|z|^{n-1}-\beta x|z|^{n}+A x$

In Eqs. 2 and 3 [4], $F(t)$ denotes the total damping force predicted by the model, $c_{0}$ is the viscous damping coefficient, $k_{0}$ is the stiffness coefficient, $\times 0$ is the initial displacement of the spring to compensate for the effect of accumulator, and $z$ is the evolutionary variable which is generally expressed in the differential form. The remaining parameters are the ones that influence the shape of the hysteresis curve. Determination of these parameters using different techniques is known as model fitting. Since there are eight parameters to be defined, simple trial and error method would be impractical. Hence, a genetic algorithm (GA) provided in the optimization toolbox of MATLAB was used for the purpose. GA is basically a search algorithm 


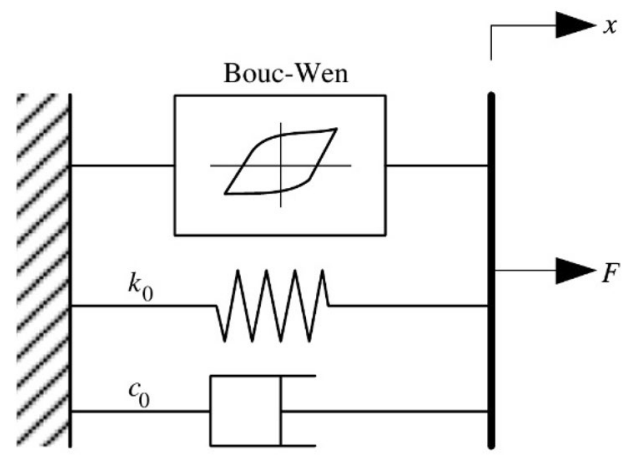

Fig. 3 Simple Bouc-Wen model [13]

that looks for the best of the combination of given parameters within the given range to generate data that are very close to given experimental data. The error between the generated and experimental data is evaluated using an error function (or fitness function). The fitness function [14] used in this study is given by Eq. 4 .

Fitness $=\frac{\sqrt{\frac{1}{n} \sum_{i=1}^{n}\left(F_{d, i}^{\exp }-F_{d, i}^{\mathrm{Fit}}\right)^{2}}}{\sqrt{\frac{1}{n} \sum_{i=1}^{n}\left(F_{d, i}^{\exp }-\left(\sum_{i=1}^{n} F_{d, i}^{\mathrm{Fit}}\right)\right)^{2}}}$

Here, $n$ is the number of samples, $F_{d}^{\exp }$ is the force obtained from experiments, and $F_{d}^{\text {rit }}$ is the force obtained from the model. For each combination of parameter values, the damping force was calculated using Eqs. 2 and 3 that were represented in MATLAB Simulink as shown in Fig. 4.

\subsection{Application of MR damper to seat suspension}

One of the prime applications of Lord MR damper RD-8040-1 is suppressing the vibration of driver's seat in commercial vehicles. Since commercial vehicles do not have the type of sensitive, advanced and expensive suspension fitted in passenger vehicles, the drivers of commercial vehicles experience fatigue and uneasiness due to long hours of work. Instead of upgrading the suspension of the entire vehicle, which is quite expensive, there is a cheaper alternative in the form of suspension for the driver's seat. The vibrations coming from the vehicle chassis are prevented from getting transmitted to the body of the driver by introducing a spring and damper between the driver seat and the vehicle chassis as shown in Fig. 5.

The seat suspension is modeled as a single-degreeof-freedom spring-mass system. In the case of passive suspension, the damping coefficient of the damper is a

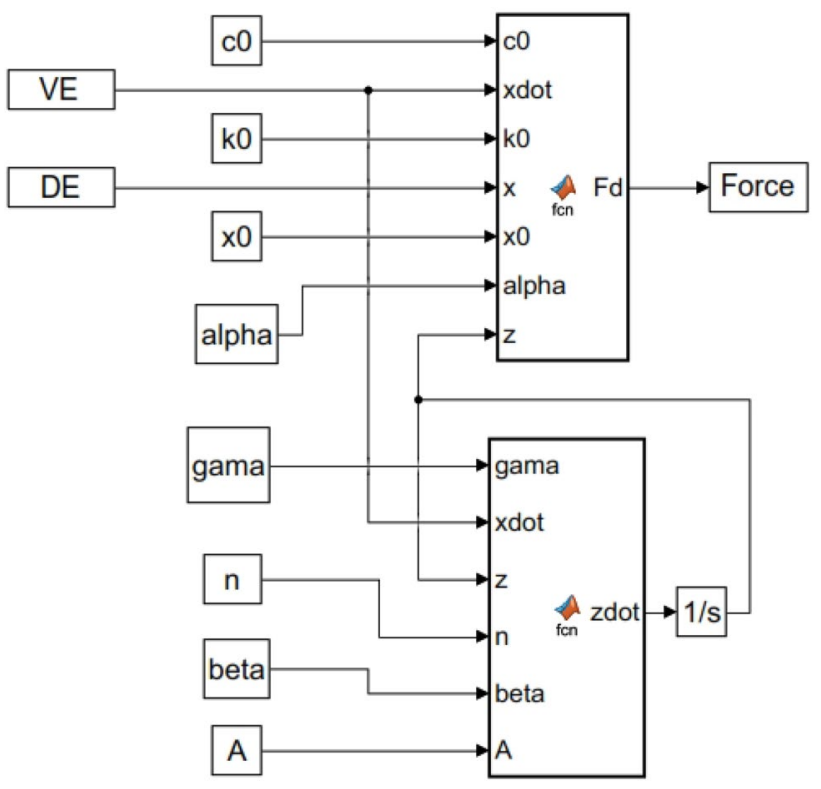

Fig. 4 Simulink blocks for Bouc-Wen model

fixed parameter based on the damper design. In the case of semi-active seat suspension, the damper used is a MR damper whose equivalent damping coefficient can be varied in real time within milliseconds by changing the value of current supplied to the MR damper.

\section{Experimental results and discussion}

The plot of load versus displacement for different values of current at different loading frequencies is shown in Fig. 6a-e. Assuming negative values of displacement and force to be compression stroke and positive values to be rebound or extension stroke, the plot to the left of the

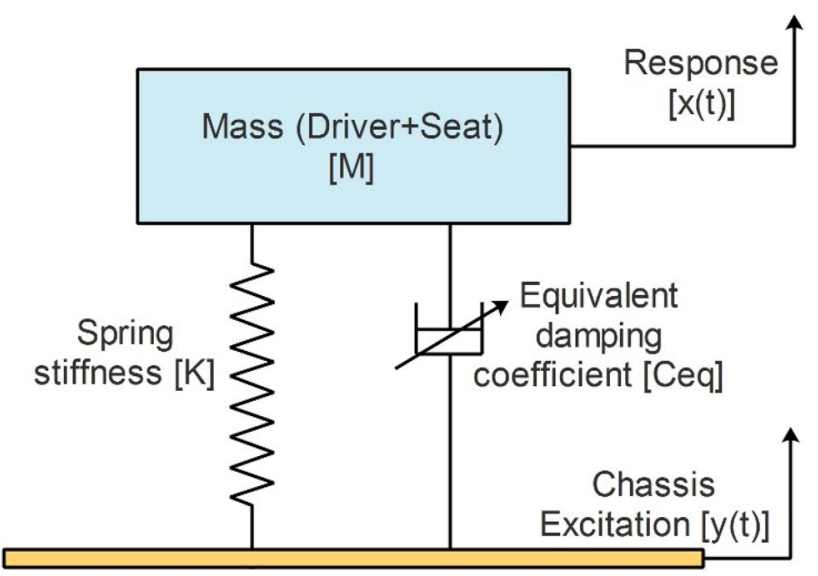

Fig. 5 Schematic of seat suspension 
ordinate is compression stroke and to the right of the ordinate is rebound or extension stroke. Similarly, the values of force above the abscissa are extension loads and the values of force below the abscissa are compression loads. The curve is traced clockwise as the damper is excited experimentally. The load versus displacement plots show that for any given frequency of input oscillations, the damping force increases with an increase in the current supplied to the MR damper. Since the area under the force-displacement curve gives the singlecycle energy dissipation, it can be observed from the load versus displacement plots that higher values of current supplied lead to greater energy dissipation by the MR damper.

The load versus displacement plots for different frequencies of oscillations at three fixed levels of current, $0 \mathrm{~A}$,

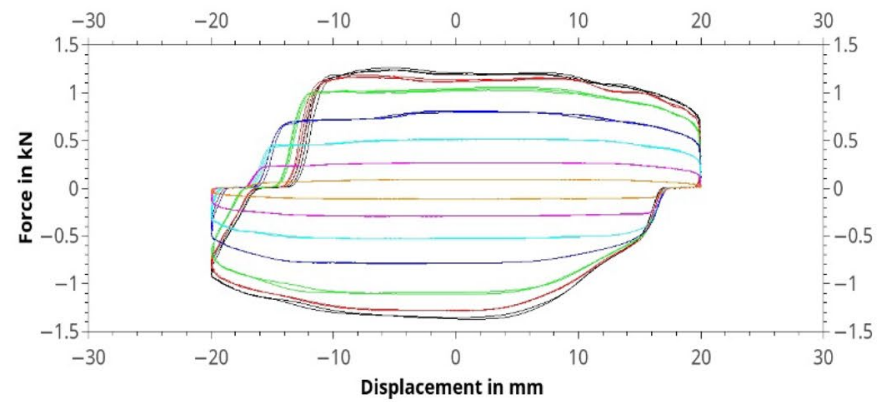

(a)

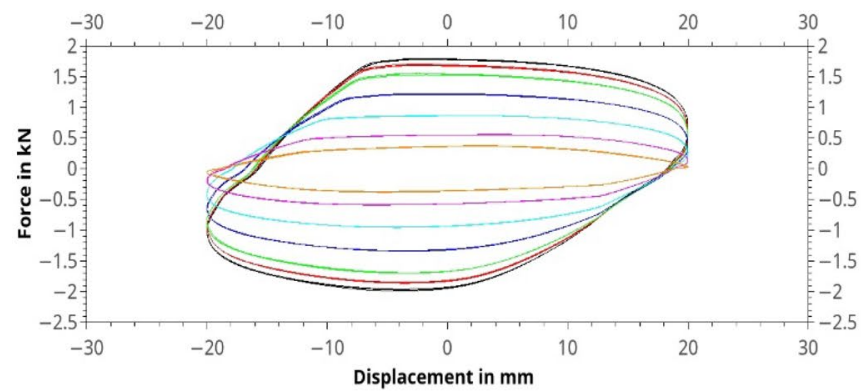

(c)

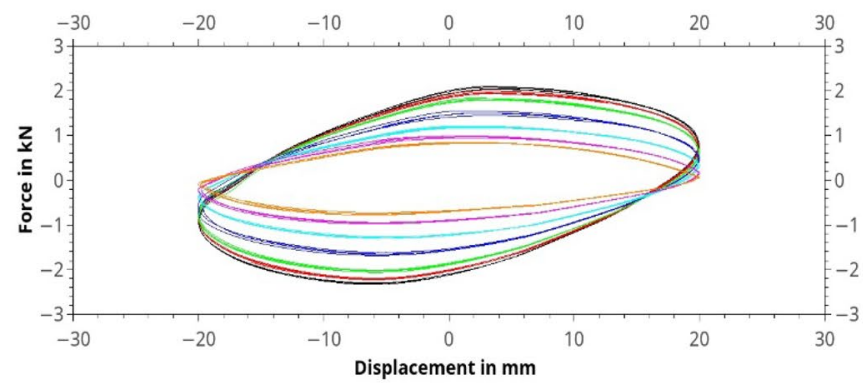

(e)
$0.5 \mathrm{~A}$ and $1 \mathrm{~A}$, are shown in Fig. 7a-c. At 0 A current, the MR damper works as a passive damper. Damper velocity is directly proportional to the product of frequency and stroke length. Since stroke length is kept constant for all experimental runs, an increase in frequency causes a proportional increase in damper velocity. The nature of a passive viscous damper is to give damping force proportional to the damper velocity as given by Eq. 5 .

$F_{d}=C_{e q} \cdot \frac{\mathrm{d} x}{\mathrm{~d} t}$

Here, $C_{\text {eq }}$ is the equivalent damping coefficient of the damper and $x$ is the damper displacement. For any given current, we can observe from the plots in Fig. $7 a-c$ that the damping force and energy dissipated by damper both increase with an increase in frequency. This demonstrates

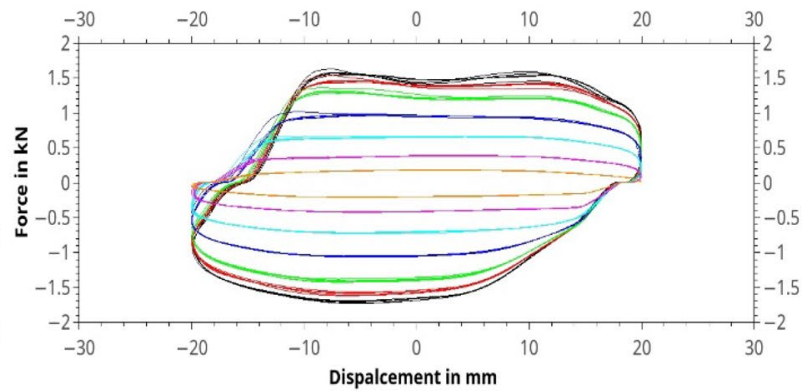

(b)

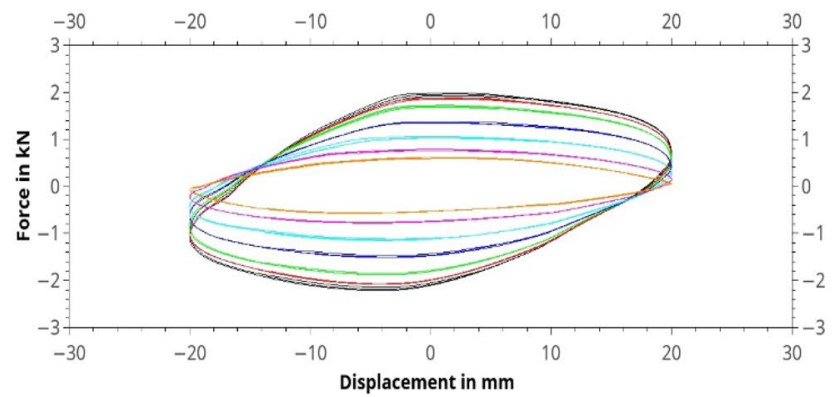

(d)

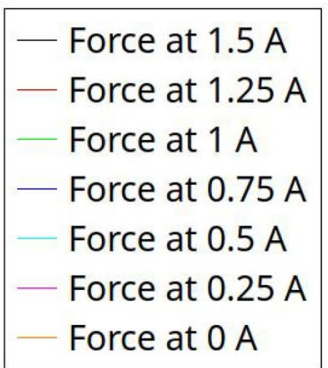

Fig. 6 a Force versus displacement at $0.4 \mathrm{~Hz}$. b Force versus displacement at $1.03 \mathrm{~Hz}$. c Force versus displacement at $2.07 \mathrm{~Hz}$. d Force versus displacement at $3.1 \mathrm{~Hz}$. e Force versus displacement at $4.14 \mathrm{~Hz}$ 


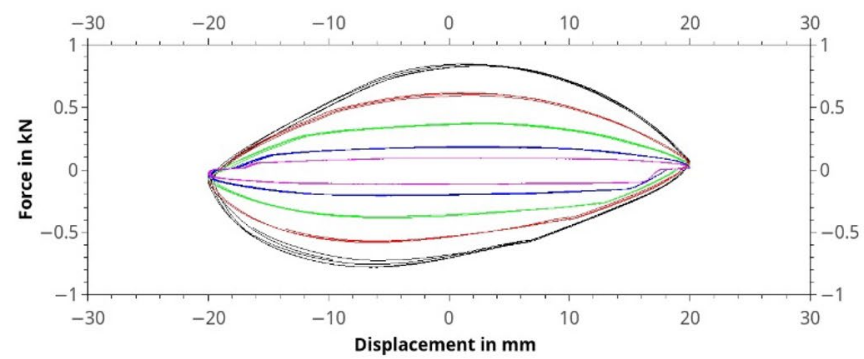

(a)

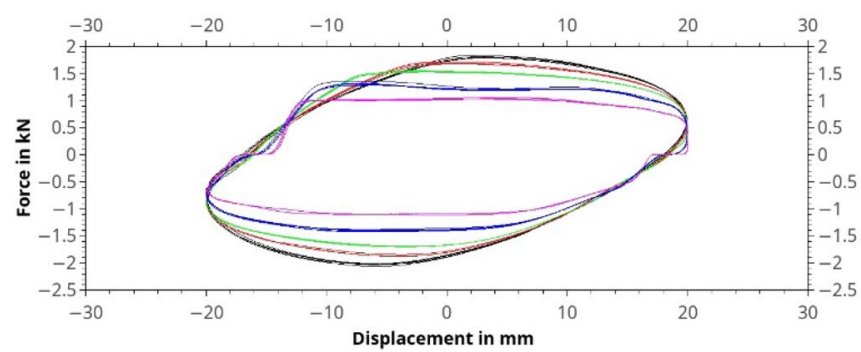

(c)

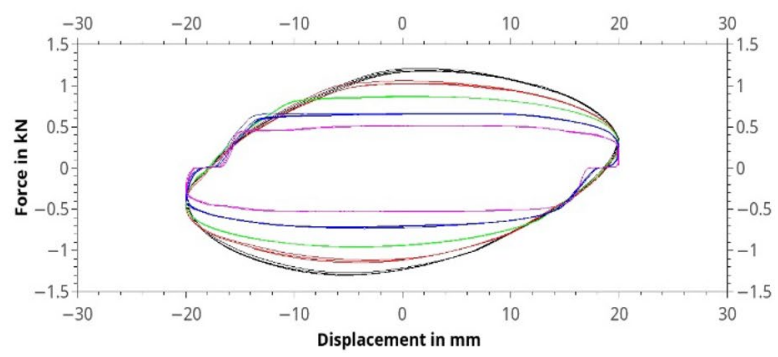

(b)

Fig. 7 a Force versus displacement at $0 \mathrm{~A}$ current. b Force versus displacement at $0.5 \mathrm{~A}$ current. c Force versus displacement at $1 \mathrm{~A}$ current

that the Lord MR damper model RD-8040-1 can be used as a damper in passive and semi-active suspension systems.

Figure 8 shows a plot of maximum damping force versus velocity amplitude of the damper. At $0 \mathrm{~A}$ current, the plot is a straight line passing through the origin as is the case in any typical passive viscous damper. At higher current values, the slope of the plot increases and it gives progressively higher values of maximum damping force for the same velocity amplitude. Assuming negative values of velocity and force to be compression stroke and positive values to be rebound or extension stroke, the maximum force versus velocity amplitude plot will be in the third quadrant for compression stroke and in the first quadrant for extension stroke. This behavior of the MR damper is utilized in designing a semi-active suspension system for commercial vehicle seat.

Dynamic range of an MR damper is defined as the ratio of the maximum damping force at full current to the maximum damping force at no current. It is a non-dimensional number, and the value of full current for Lord RD-8040-1 as given in [10] is between 1 and $2 \mathrm{~A}$. The plot of dynamic range versus frequency in Fig. 9 shows that dynamic range reduces drastically with an increase in frequency. Since dynamic range is an important parameter in effective working of a semi-active suspension system, the MR damper Lord Rd-8040-1 is more suitable for low-frequency applications in the range of $0.5-3 \mathrm{~Hz}$.

Using Eq. 1 and numerical integration of experimental plots of force versus displacement, equivalent damping
Fig. 8 Maximum force versus velocity amplitude

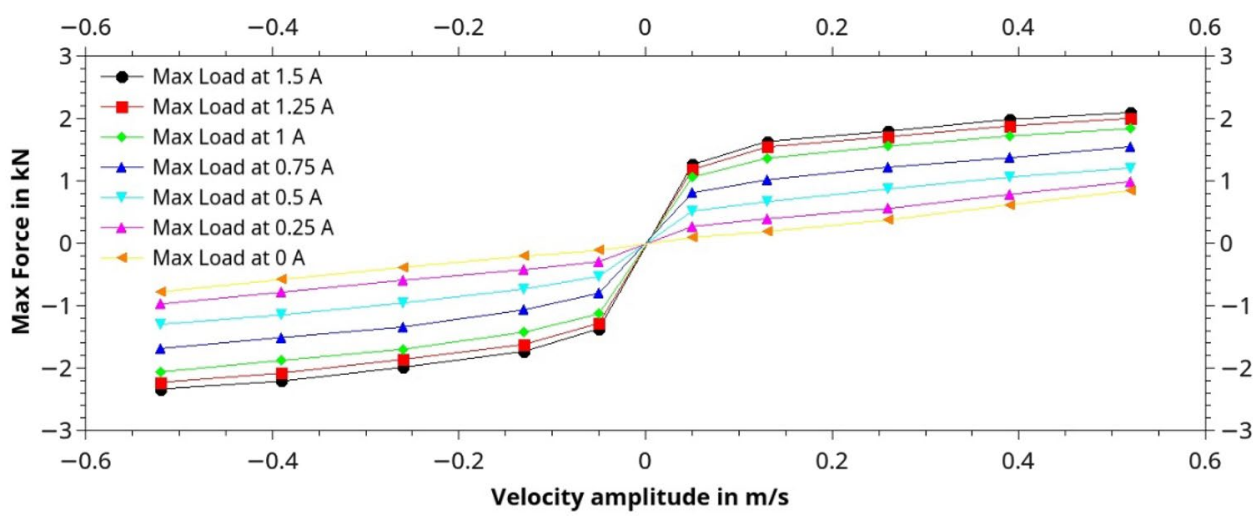


Fig. 9 Dynamic range versus frequency for Lord RD-8040-1 damper

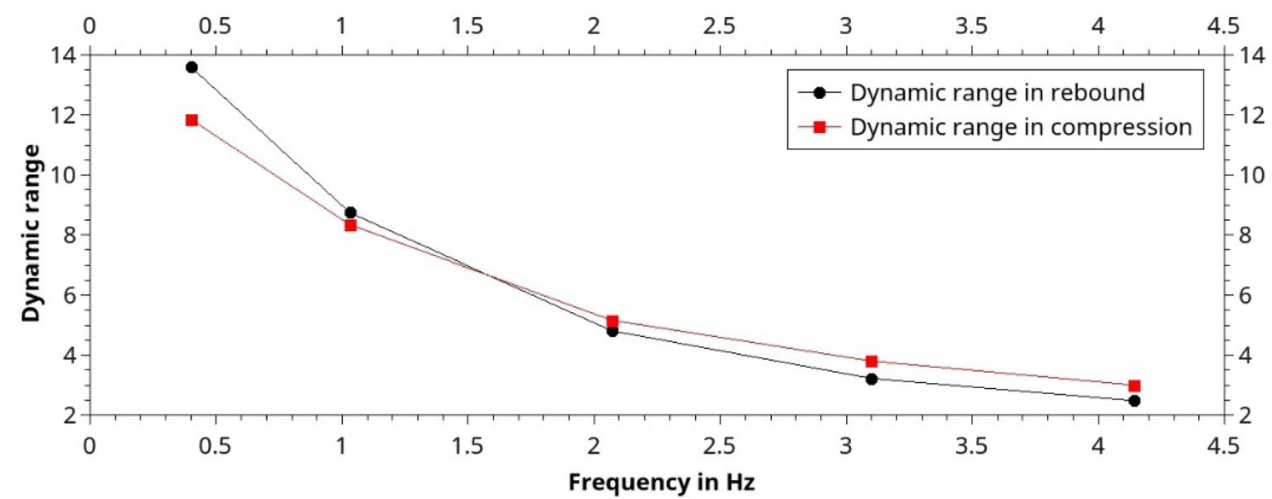

Table 2 Energy dissipated and equivalent damping coefficient of MR damper at different values of current supplied at input excitation frequency of $2.07 \mathrm{~Hz}$ and excitation amplitude of $20 \mathrm{~mm}$

\begin{tabular}{lll}
\hline $\begin{array}{l}\text { Current supplied } \\
\text { (A) }\end{array}$ & $\begin{array}{l}\text { Energy dissipated } \\
W(\mathrm{~J})\end{array}$ & $\begin{array}{l}\text { Equivalent damp- } \\
\text { ing coefficient } C_{\text {eq }} \\
(\mathrm{kNs} / \mathrm{m})\end{array}$ \\
\hline 0 & 21.8029 & 1.334 \\
0.5 & 56.9029 & 3.4816 \\
1 & 94.4915 & 5.7814 \\
\hline
\end{tabular}

Table 3 Bouc-Wen model parameters

\begin{tabular}{lll}
\hline SI. no. & Parameter & Value \\
\hline 1 & $c_{0}(\mathrm{Ns} / \mathrm{m})$ & $2069.6 I-833.4$ \\
2 & $k_{0}(\mathrm{~N} / \mathrm{m})$ & $6782 l^{2}+18045 /+12907$ \\
3 & $x_{0}(\mathrm{~m})$ & 0.012982 \\
4 & $a(\mathrm{~N} / \mathrm{m})$ & $-128.59 l^{2}+639.98 I-276.47$ \\
5 & $\gamma(/ \mathrm{sq} \mathrm{m})$ & 44.616 \\
6 & $n$ & 9.927883 \\
7 & $\beta(/ \mathrm{sq} \mathrm{m})$ & 24.768 \\
8 & $A$ & 19.903 \\
\hline
\end{tabular}

coefficient of MR damper at $2.07 \mathrm{~Hz}$ excitation frequency and $20 \mathrm{~mm}$ amplitude of excitation for different levels of current supplied is given in Table 2 .

To simulate the behavior of the MR damper under forced vibration, a mathematical model of the MR damper is developed based on the Bouc-Wen model. The GA used in this study consisted of a population size of 200 with 20 generations and 50 stall generations. Since the differential equation involved is fairly complex, a fourth-order Runge-Kutta method was used for computation of the model parameters. These parameters are shown in Table 3.

The plots of force versus displacement for the MR damper showing experimental and simulated results at current values of $0 \mathrm{~A}, 0.5 \mathrm{~A}$ and $1 \mathrm{~A}$ for $2.07 \mathrm{~Hz}$ excitation frequency are shown in Fig. 10a-c. Similarly, the plots of force versus time for the MR damper showing experimental and simulated results at current values of $0 \mathrm{~A}, 0.5 \mathrm{~A}$ and $1 \mathrm{~A}$ for $2.07 \mathrm{~Hz}$ excitation frequency are shown in Fig. 11a-c.

The plots show that there is a reasonable agreement between the experimental and simulated results. The mathematical modeling was done for one particular frequency of excitation to demonstrate the method to be used to get the mathematical model of MR damper behavior. Hence, following the same procedure, mathematical models can be developed to predict the behavior of the MR damper at various other current levels and other excitation frequencies and a more generalized model can be obtained for damper behavior prediction. These can be further used to design semi-active control strategy for the seat suspension using MR damper.

Assuming mass of human body to be $60 \mathrm{~kg}$ and that of the seat to be $20 \mathrm{~kg}$, the total mass of the single degree of freedom system $\mathrm{m}$ is $80 \mathrm{~kg}$. The spring stiffness of the system $\mathrm{k}$ is assumed to be $16 \mathrm{kN} / \mathrm{m}$. Based on these values, the natural frequency of the undamped system is $2.251 \mathrm{~Hz}$. Since vehicle chassis vibration is predominantly in the region of $0.5-7 \mathrm{~Hz}$, the natural frequency falls within this range and use of a suitable damper becomes necessary to avoid resonance of the seat suspension. The critical damping coefficient for this system is $2.2627 \mathrm{kNs} / \mathrm{m}$. The response of the system to a pulse input of displacement amplitude of $20 \mathrm{~mm}$ for different values of current supplied is shown in Fig. 12.

We can see that the response of the system at $0 \mathrm{~A}$ current is similar to the response of an underdamped system. At higher values of current, like $0.5 \mathrm{~A}$ and $1 \mathrm{~A}$, the response of the system is similar to that of an overdamped system. This behavior is corroborated by the analytical results provided in Table 2 which shows that the equivalent damping of the MR damper at $0 \mathrm{~A}$ is less than the critical damping coefficient of the system and the equivalent damping of the MR damper at $0.5 \mathrm{~A}$ and $1 \mathrm{~A}$ is greater than the critical damping coefficient of the system. Hence, it has been demonstrated that by tuning the current supplied to the MR damper, the same damper can make the system 


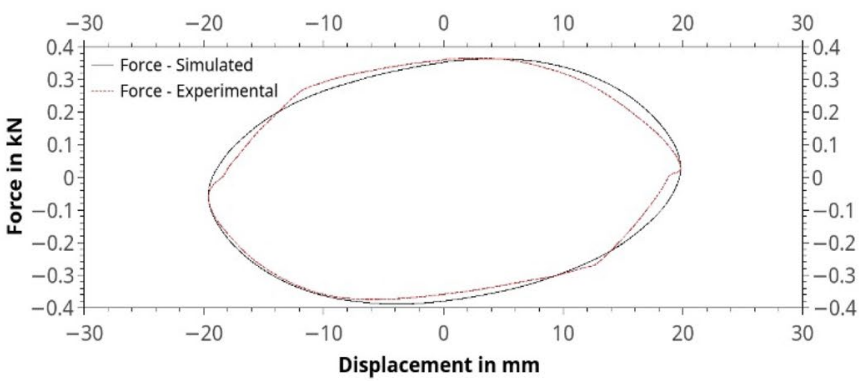

(a)

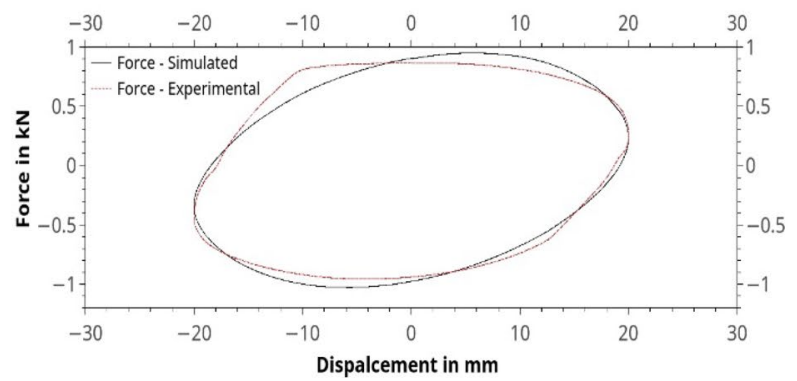

(b)

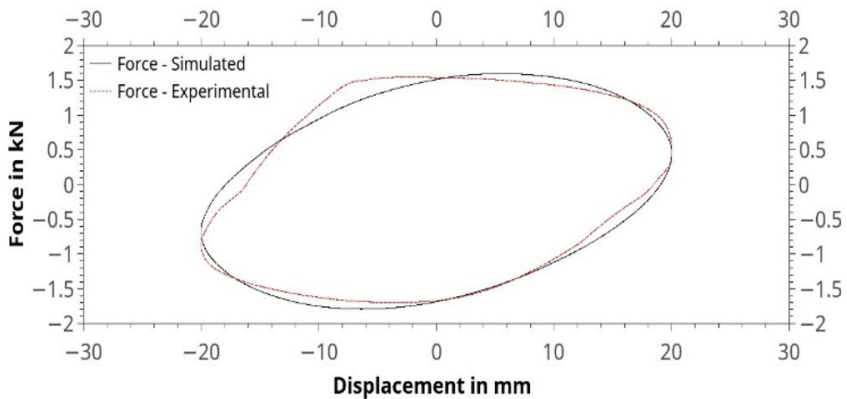

(c)

Fig. 10 a Force versus displacement for $2.07 \mathrm{~Hz}$ excitation frequency at $0 \mathrm{~A}$ current. b Force versus displacement for $2.07 \mathrm{~Hz}$ excitation frequency at $0.5 \mathrm{~A}$ current. c Force versus displacement for $2.07 \mathrm{~Hz}$ excitation frequency at $1 \mathrm{~A}$ current

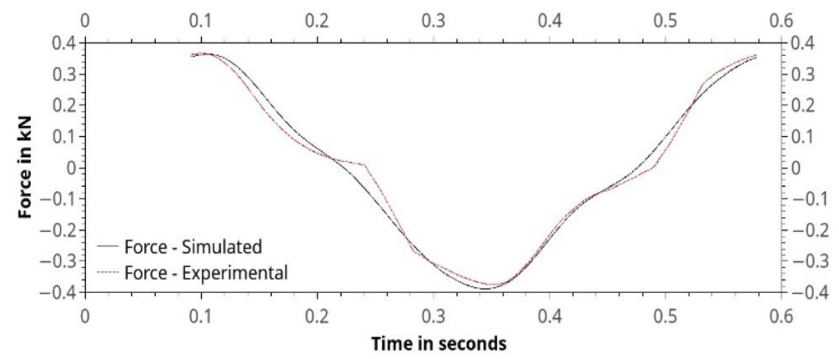

(a)

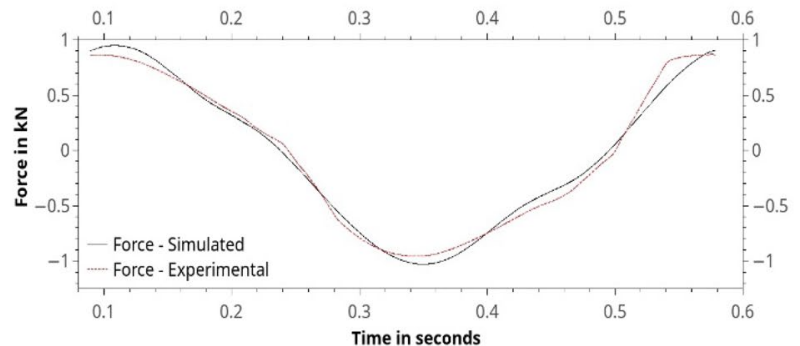

(b)

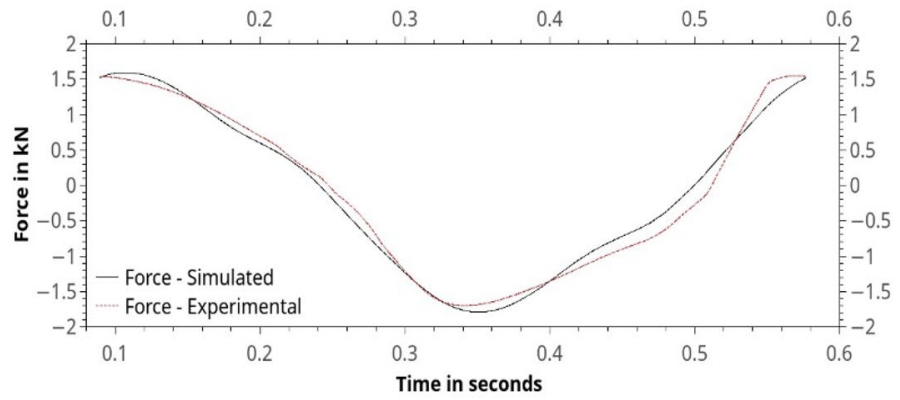

(c)

Fig. 11 a Force versus time for $2.07 \mathrm{~Hz}$ excitation frequency at $0 \mathrm{~A}$ current. b Force versus time for $2.07 \mathrm{~Hz}$ excitation frequency at $0.5 \mathrm{~A}$ current. c Force versus time for $2.07 \mathrm{~Hz}$ excitation frequency at $1 \mathrm{~A}$ current 

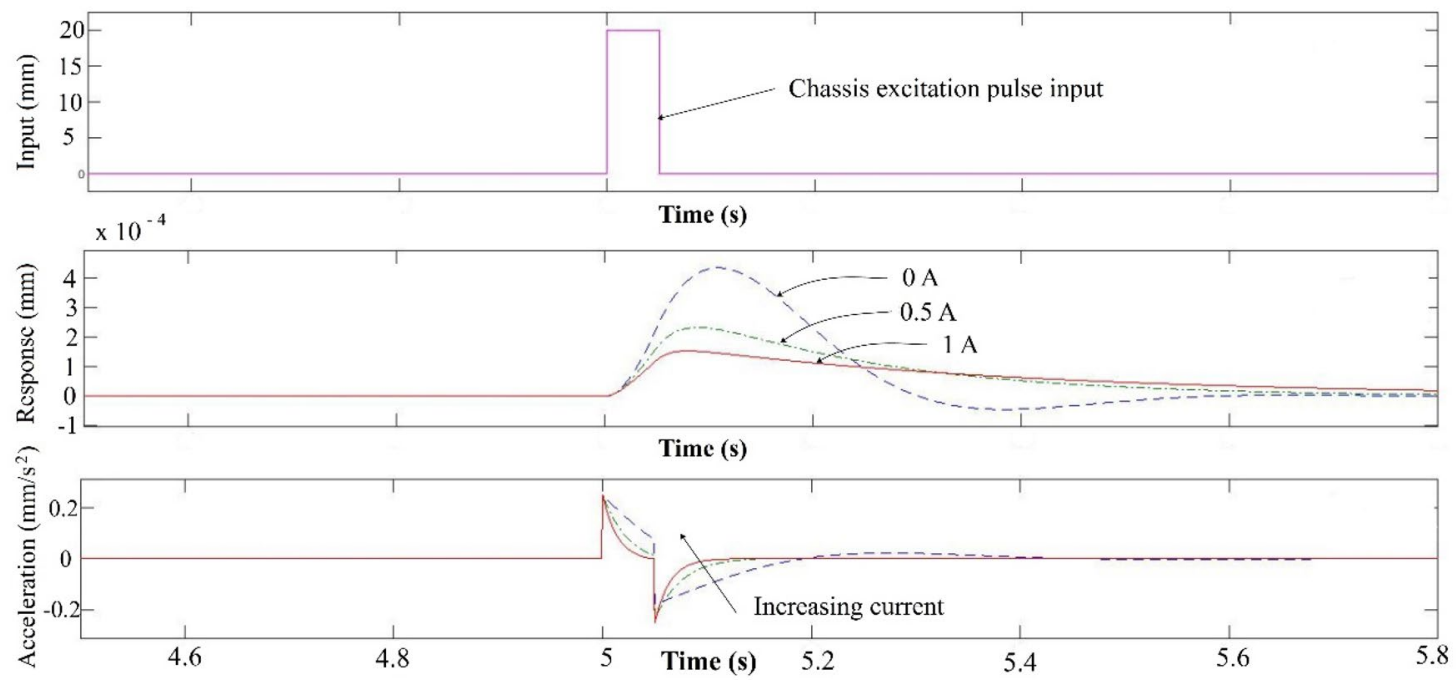

Fig. 12 Response of seat suspension system at 0 A, 0.5 A and 1 A, obtained from MATLAB Simulink

behave as an underdamped, critically damped or overdamped system of vibration.

\section{Conclusions}

A commercially available MR damper was evaluated in a damping force testing machine at various excitation frequencies and current supplied. Plots of force versus displacement show that damping force was increasing with velocity as well as current supplied. Calculation of area of the force versus displacement loops leads to evaluation of energy dissipated values which in turn gave values of equivalent damping of the MR damper. The increase in equivalent damping with current supplied and plots showing the high dynamic range of MR damper at frequencies between 0.5 and $3 \mathrm{~Hz}$ made the MR damper suitable for application in commercial vehicle driver's seat suspension. Mathematical model of the MR damper behavior was developed using Bouc-Wen hysteresis operator and genetic algorithm (GA) provided in optimization toolbox of MATLAB. A good match between the simulated and experimental plots confirms the veracity of the method used. It was successfully shown that by controlling the current supplied to the MR damper, the suspension can be made to work as an underdamped, critically damped or overdamped system. The current supplied also controls the amount of energy dissipated by the MR damper in one cycle of input oscillation. These can be used to design a semi-active control strategy for the seat suspension using MR damper to provide a comfortable and fatigue-free ride.
Acknowledgements The authors acknowledge the Impacting Research Innovation and Technology (IMPRINT) Project No. IMPRINT/2016/7330 titled with Development of Cost-Effective Magneto-Rheological (MR) Fluid Damper in Two-wheeler and Four Wheelers Automobile to improve ride comfort and stability funded by Ministry of Human Resource Development (MHRD) and Ministry of Road Transport and Highways, Government of India.

\section{Compliance with ethical standards}

Conflict of interest The authors declare that there is no potential conflict of interest involved in the publication of this research article.

\section{References}

1. Cortes RJA, Villarreal-Gonzalez LS, Martinez MM (2005) Characterization, modeling and simulation of magnetorheological damper behavior under triangular excitation. Adv Technol Mater Mater Process J 7(2):135

2. Zhang HH, Liao CR, Chen WM, Huang SL (2006) A magnetic design method of MR fluid dampers and FEM analysis on magnetic saturation. J Intell Mater Syst Struct 17(8-9):813-818

3. Guan XC, Guo PF, Ou JP (2011) Modeling and analyzing of hysteresis behavior of magneto rheological dampers. Proc Eng 14:2756-2764

4. Spencer BF Jr, Dyke SJ, Sain MK, Carlson J (1997) Phenomenological model for magnetorheological dampers. J Eng Mech 123(3):230-238

5. Sapiński B, Filuś J (2003) Analysis of parametric models of MR linear damper. J Theor Appl Mech 41(2):215-240

6. Song X, Ahmadian M, Southward SC (2005) Modeling magnetorheological dampers with application of nonparametric approach. J Intell Mater Syst Struct 16(5):421-432

7. Dyke SJ, Spencer BF Jr, Sain MK, Carlson JD (1996) Modeling and control of magnetorheological dampers for seismic response reduction. Smart Mater Struct 5(5):565 
8. Peng GR, Li WH, Du H, Deng HX, Alici G (2014) Modelling and identifying the parameters of a magneto-rheological damper with a force-lag phenomenon. Appl Math Model 38(15-16):3763-3773

9. Lee $Y$, Jeon $D$ (2002) A study on the vibration attenuation of a driver seat using an MR fluid damper. In: Electrorheological fluids and magnetorheological suspensions, pp 70-76

10. RD-8040-1 MR Damper (short stroke) data sheet. http://www. lordmrstore.com/lord-mr-products/rd-8040-1-mr-damper-short -stroke. Accessed on 10 Dec 2018

11. Rao SS, Yap FF (2011) Mechanical vibrations, vol 4. Upper Saddle River, Prentice hall, $\mathrm{p} 179$

12. Guglielmino E, Sireteanu T, Stammers CW, Ghita G, Giuclea M (2008) Dampers and vehicle modelling. In: Guglielmino E,
Sireteanu T, Stammers CW, Ghita G, Giuclea M (eds) Semi-active suspension control. Springer, Berlin, p 22

13. Wang DH, Liao WH (2011) Magnetorheological fluid dampers: a review of parametric modelling. Smart Mater Struct 20(2):023001

14. Peng Y, Yang J, Li J (2018) Parameter identification of modified Bouc-Wen model and analysis of size effect of magnetorheological dampers. J Intell Mater Syst Struct 29(7):1464-1480

Publisher's Note Springer Nature remains neutral with regard to jurisdictional claims in published maps and institutional affiliations. 